\title{
A Joint Learning Process for Stakeholders and Insider Peacebuilders: A Case Study from Southern Thailand
}

\author{
Norbert Ropers and Mathus Anuvatudom
}

\section{Introduction: From Conflict Analysis to Peacebuilding Impact}

In 2012, two well-established international nongovernmental organizations (INGOs) in the peacebuilding field, Conciliation Resources and Saferworld, published a joint report entitled "From Conflict Analysis to Peacebuilding Impact” (Hiscock and Dumasy 2012). This report was based on 18 conflict studies across a broad range of contexts, all focused on building the capacities of local actors to engage in participatory forms of conflict analysis as well as utilizing the insights gained for strategizing peacebuilding initiatives. The report's main conclusion was that adequate conflict analysis is a key precondition for all types of effective peacebuilding initiatives. Two other notable conclusions were that the process and the ownership of the conflict analysis are as important as the results of the analysis.

That study resonates with the current authors' similar experiences in the context of the Insider Peacebuilders Platform (IPP) for the Deep South of Thailand. ${ }^{1}$ The IPP group was created at the beginning of 2011 as a joint initiative of a number of academic institutes in the Conflict and Peace Studies field, one state-based institution, and several academic and civil society organizations (CSOs). ${ }^{2}$ This platform was inspired by the observations of peace scholars and practitioners that, although civil society has been increasingly engaged in the region since 2007, few efforts have been put forward to bring the different actors together as a way to improve their joint strategizing and explore possibilities for more effective collaboration.

Intensive discussions within the core IPP team initially focused on how best to develop such an approach in light of the earlier failures of several 
well-intentioned efforts to promote collaboration and coordination among peacebuilding activists. The failure of these efforts largely centered on the difficulty of finding a method to best pursue these goals. We then came across a concept developed previously by peacebuilding researcher and activist Robert Ricigliano (2003), the Network of Effective Action (NEA). Apart from the need for a holistic approach to peacebuilding, he emphasized utilizing creative ways to develop a common theory of action.

Ricigliano furthermore highlighted that instead of promoting this method within the context of a formalized network and an explicit division of responsibilities, it would be better achieved within a rather "chaordic" arrangement. By this he meant that the collaboration should be self-organizing, decentralized and flexible, and that the network should be as inclusive as possible, allowing space for joint learning.

It was the latter point that was most attractive to us. We decided that the initial focus of the IPP should be on joint learning-a joint conflict analysis to create a common understanding of the main challenges towards peacebuilding. We also expected that this joint learning might promote trust and confidence building among the participants that could later assist collaboration on joint projects. Finally, to emphasize the learning aspect of the IPP, we envisioned the joint meetings as events that would start with providing knowledge and skills on the assessment of conflicts in general which would then be applied to the specific case of Southern Thailand. We used the term conflict analysis tools to describe this process. $^{3}$

The selection and sequencing of the tools was guided by three basic considerations:

1. The tools should together support a systemic understanding of the main features and drivers of the conflict and not just assemble data (Koerppen, Ropers, and Giessmann 2011; Ricigliano 2012; Schirch 2013).

2. The sequencing of the tools should support step-by-step trust and confidence building among the participants. For this purpose we decided that tools which offered chances for consensus building even among adversaries, like the mapping of actors and their relationships, should come before those that could easily generate confrontational disputes, like the parties' historical narratives.

3. The tools should allow visualizations in the form of diagrams to support creativity within small working groups. For this purpose we screened a reasonable sample of the available literature on conflict analysis (Leonhardt 2002; Fisher et al. 2005; SDC 2005; SIDA 2006; USAID 2012).

Regarding the composition of the IPP, our intention was not only to invite persons with an explicit understanding of working for "negative peace" in the sense of ending the violence, but also individuals close to one or the other party with an interest in changing the injustices and deeper drivers of conflict in the 
region. In the end, the IPP not only comprised peacebuilders striving for some kind of impartiality or multipartiality, but also numerous political activists arguing for nonviolent change in the region. We decided to summarize these two groups under the category of Stakeholders and Insider Peacebuilders in order to emphasize that the IPP comprises a broad spectrum of persons with different motives, positions, and interests.

This article aims to document the application of five key tools utilized in the context of the IPP between September 2011 and June 2012, as well as discuss the group dynamics and the learning that accompanied the process. We have also collected feedback from participants in the context of an Action Research project. The results have been published separately (Chaijaroenwatana et al. 2013). In this article our aim is twofold: we wish to assess the usefulness of Ricigliano's concept, and also to share our insights on how to improve its effectiveness.

The following section provides a brief overview of the conflict's context and describes the development of the IPP, particularly with respect to the participants and their interests, and the organization of the workshops and other gatherings. In the main part we will outline the five key tools and how the participants made use of these tools, and then we will summarize the results as well as publish the feedback of the participants. In the final section we will review the lessons learned from this experience and also summarize a number of open questions requiring further research.

The IPP collaboration is an ongoing process. After the focus on the five conflict analysis tools covered in this article, the group began working on roadmaps for peace processes and engaging with the Track-1 peace dialogue efforts undertaken between February 2013 and the beginning of 2014. We will reflect on these more recent developments in a future article while limiting our focus here to the insights gathered from the conflict analysis phase.

\section{The Case of Southern Thailand and the Development of the Insider Peacebuilders Platform (IPP)}

The conflict in the Deep South of Thailand has been well researched since its reescalation in 2004 . The majority of this research has concluded that the conflict is deeply rooted in the history of the region involving the Thai state and the local Malay Muslim and Malay Patani populations, respectively. Essentially, it can best be described as an ethno-political legitimacy conflict (McCargo 2009; 2012; Abuza 2009; Satha-Anand 2009; Joll 2010; Barter 2011; Jitpiromsri and Engvall 2013; Jory 2013). ${ }^{4}$

This research has also emphasized that this particular conflict-as in many similar cases-has developed a complex dynamism of its own, including the self-reproducing nature of high levels of violence as well as the interference 
of non-politically driven violence. Finally, another feature that has triggered significant research is the enigmatic character of the resistance movement and its organizational set up. But this latter aspect has somewhat changed in light of the Peace Dialogue Process, which the Thai National Security Council (NSC) and the leading resistance organization, the National Revolutionary Front (Barisan Revolusi Nasional: BRN), agreed to on February 28, 2013 (Lamey 2013).

This process is currently in limbo due to the transitional government situation in Thailand, but it had already run into difficulties due to the lack of inclusivity, political will, and sound strategic planning on the part of both sides (IPP 2014; McCargo 2014; Tuansiri and Pathan 2014). Still, a large number of insiders agree that sooner or later a new, politically driven peace initiative is necessary to transform the conflict in a sustainable manner (Jitpiromsri 2014).

During the past decade, a number of activities have been initiated to promote peace. While the majority of these efforts has focused on security- and development-related programs, there has also been a significant increase in initiatives by CSOs, academic institutions and individuals linked to various state institutions, particularly since 2007. As mentioned above, this was the context in which the idea of the IPP was proposed as a means of creating a kind of neutral space for peacebuilders and politically active stakeholders within the conflict (therefore called "insiders") to collectively analyze the conflict and explore ways to transform it. This idea was endorsed by the previously mentioned constituent entities of the IPP who appointed the members of a core (management) team.

The selection of participants by this team was based on three basic considerations: first, persons with connections to some kind of reference group so that they could function as multipliers with respect to their home organization or constituency; second, peacebuilders and stakeholders who ideally represent the full spectrum of opinions surrounding the peaceful transformation of the conflict; and third, organizational affiliations and individual characteristics as well as adequate representation of women and youth. Based on these criteria the individual features would become important reference points for expanding the group as well as occasionally rotating participants to enhance the overall outreach of the IPP initiative.

Altogether approximately 50 persons participated in five workshops and several follow-up working groups that took place between September 2011 and June 2012. The majority of these individuals were residents of the southern border region. They included state officials, religious leaders, business people, members of women and youth groups, teachers, academics, as well as civil society activists working on human rights, environmental and cultural issues, community development, education, peacebuilding, and political and governance reform.

As for the representation of identity groups, we regularly noticed an overrepresentation of Malay Muslims in the IPP compared to Thai Buddhists and Thai Chinese. ${ }^{5}$ This was mainly due to the fact that more than $80 \%$ of the people living 
in the region belong to this group, and it also reflects this group's strong interest in the purpose of the IPP initiative. Several of the Thai Buddhist participants hailed from outside of the region, mainly from Bangkok, because they had either official responsibilities related to the South or a personal interest in conflict transformation.

For the majority of participants, the IPP initiative provided a unique, but also challenging, opportunity to reflect upon and discuss their different perspectives and experiences regarding the conflict and its transformation. Some of them were attracted to the question of how the multiplicity of Track-2 to Track-3 peace initiatives in which they were involved-from dialogue projects to local peace journalism-might have some kind of macro-political impact. This was an issue we also discussed in the context of the "PEACE WRIT LARGE" and "peace writ little" discourse (Chigas and Woodrow 2009). For others, the primary appeal of the initiative was the opportunity to engage with people from different backgrounds holding radically different opinions.

Both of these aspects encouraged the team to furnish the initiative with some academic features in order to emphasize the need to learn about the current state of the art of conflict analysis as well as peacebuilding, and to encourage the participants to view the conflict from the perspective of the tools provided. Also, from a very practical security point of view, all workshops and follow-up working groups were organized on the Pattani campus of the Prince of Songkla University which provided a relatively safe space for this kind of engagement.

In terms of the working process, the core team was composed of representatives from the initiating partner organizations. Before starting each two- to three-day workshop the team would brainstorm on the detailed objectives, the composition of the group, the tools to be used and the agenda. In the event, the facilitation was led by a team of two more-senior facilitators, one Thai Buddhist and one Malay Muslim. Senior team members analyzed the conflicts and considered their application to other cases. Typically, the workshop was a mix of plenary meetings and breakout groups where most of the practical work took place.

\section{The Joint Series on Conflict Analysis}

This section will describe the rationale for the selection of the five tools, provide an overview of the applied methods, and then summarize the outcome.

Conflict analysis is "a practical process of examining and understanding the reality of the conflict from a variety of perspectives" (Fisher et al. 2005, 17). A plethora of methods have been developed for this purpose over the past 40 or so years. As mentioned above, for our purpose, selection of the tools was based on their capacity to support a systemic understanding of conflict (does 
Figure 1. Joint Series of Conflict Analysis Workshops

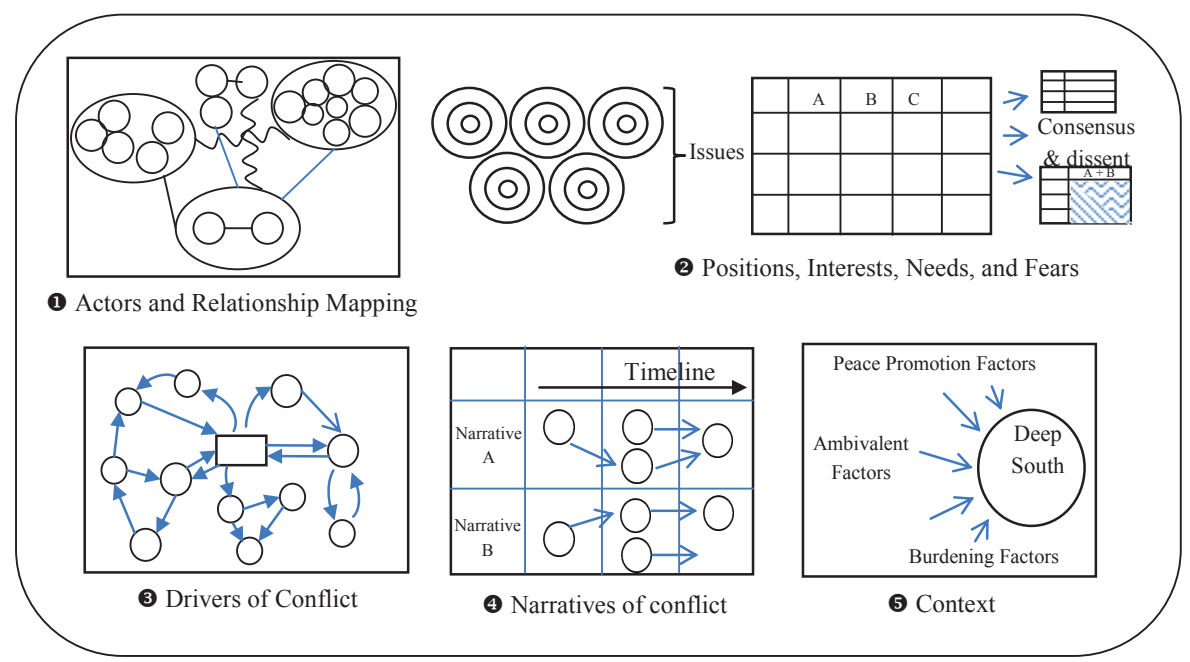

the combination of tools help to see the essence of the conflict?), build trust and confidence among the persons engaged in this exercise, and finally stimulate visualization of the issues in a practical way. While we attempted to apply all of the tools from the widely used scheme of Where, Who, Why, What, How, and When (Schirch 2013, 67-74), we began with the less difficult ones. The question we decided to leave out at this stage was the How question; that is, how the parties applied their power (violence, securitization, etc.), because we were concerned that this topic might prove to be too sensitive, especially at the beginning.

The sequencing of the five tools was based on the following questions:

1. Who are the main parties and stakeholders in the conflict? In addition, how do these actors relate to each other and how powerful are they? To address these issues, we employed the Actor-Relationship Mapping Tool, a visual technique used to illustrate the parties in the conflict and their relationships ranging from alliance to severe conflict. Participants were asked to use circles of different sizes to represent the various actors in the conflict. The size would depend on each actor's importance to the conflict. After the actors were discussed, the participants were then asked to consider the quality of the relationships among these actors.

2. What are the underlying issues that put parties in conflict with one another? In other words, what do they want to achieve? In order to differentiate between layers of issues, the widely used onion metaphor was introduced. This is a tool, which slices the onion into three layers. The outer layer represents the public positions presented by each party. The inner layer indicates their interests, or what the parties really want to achieve. Finally, the core layer portrays the needs and fears determining what they must have in the end, and what they most fear. 
3. What factors contribute to making conflicts violent and protracted? This activity focuses on the drivers of the conflict. All protracted conflicts have multiple, interlinked drivers that create the tragic self-reproduction of rivalry, confrontation, them-and-us perceptions, and violence. While one phenomenon results from a particular driver, it can then give rise to other drivers in a contiguous chain, which causes all drivers to be entangled. That is to say that most cause-effect relationships do not function in a linear fashion, but rather are linked together in a complex web relationship. These attributes reflect the fact that while each party acts to advance its respective objectives, they all in turn wind up constructing a system and generating complementary factors that drive and feed into the conflict itself. In the end, no single entity has control over the situation or the system as a whole (Koerppen, Ropers, and Giessmann 2011). Participants were first asked to choose some conflict-related phenomena and then identify factors that trigger and sustain those phenomena. Based on these causal factors, they were then asked to identify what drives the factors. With this tool, participants developed a more comprehensive understanding of why the conflict has reached its current protracted, seemingly unresolvable, stage. This enabled them to better understand the complexity of the situation and also to identify possible opportunities for intervention.

4. What are the narratives ${ }^{6}$ of the conflict from the perspectives of the key actors and stakeholders? One way to understand how the parties perceive the conflict is to be aware of the different narratives of the conflict. Certainly, there will be no single narrative or single version of history. Instead, each party has a different historical recollection of how the conflict emerged according to its own point of view. And as the conflict has broadened and deepened, so have the collection of narratives circulated among the conflicting parties. The purpose of this tool was to elicit different versions of the narratives of history in order to make the participants aware of their differing perceptions and beliefs. Participants were first asked to form groups based on their ethnicity-Malay Muslim, Thai Buddhist, and Thai Chinese. Then they elaborated their narratives and documented them on a visualized timeline. The three resulting timelines were then shared with the other groups in the plenary.

5. What is the context of the conflict? This was the last step of the process of assessing the ongoing conflict, and at the same time a first step towards identifying potential factors for conflict transformation. In this exercise the context was divided into factors that contribute to peacebuilding, obstruct peace efforts, or others that were identified as ambivalent. This tool encouraged participants to reflect on the wider geopolitical context of the conflict as well as consider the other drivers of change outside the conflict system.

This joint analysis process created a mixed picture of agreements and disagreements. Whenever possible, we encouraged the participants to work towards a synthesis or a merger of their results. For this purpose we introduced 
Figure 2. Simplified Version of Actor-Relationship Mapping

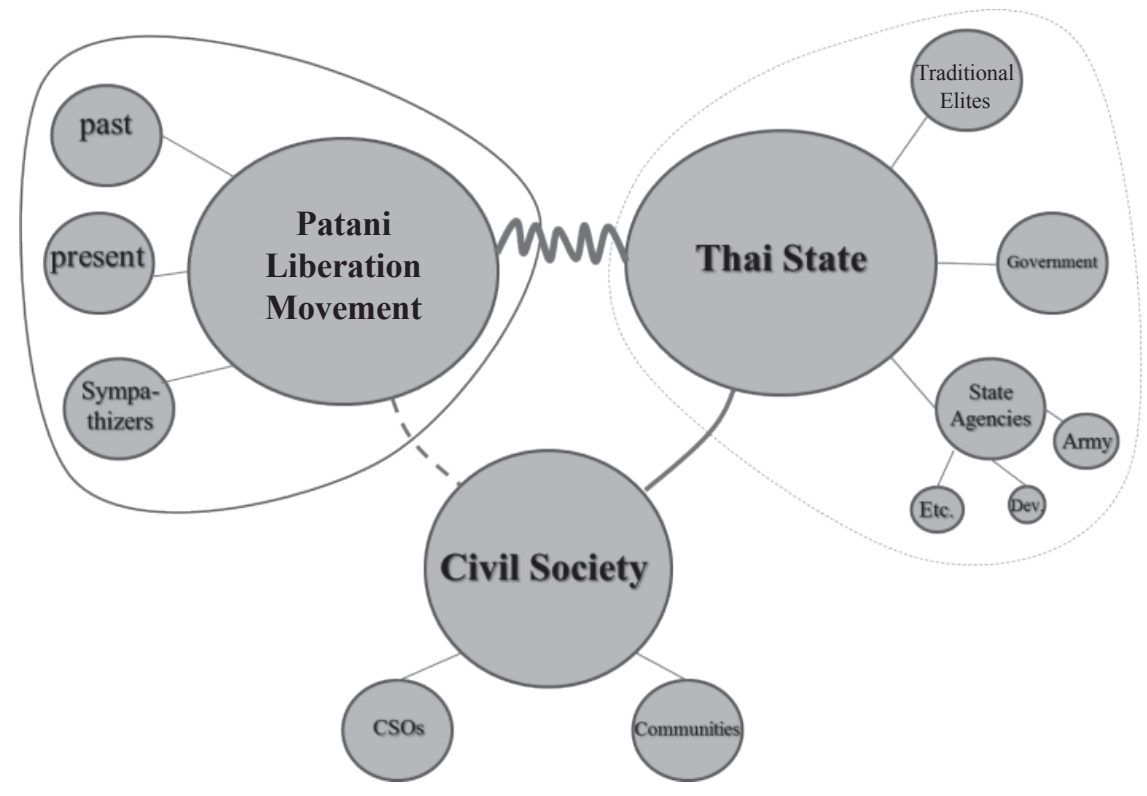

the concept of "sufficient consensus" as a guideline to facilitate compromises. This helped stimulate dynamic discussions, searches for new information, and efforts to include different perspectives and opinions into the final analysis.

In the following section we will review the results from the five tools in terms of substance and process. This process created what we believe to be the first participatory conflict analysis of the Deep South by people with close associations to the two main conflicting parties. The analysis reflects a certain level of common, multiparty understanding of the conflict. We will add some observations on the participatory process and the implications for co-ownership of the results. Please note that all diagrams are simplified for the purpose of clarity.

\section{Actor-Relationship Mapping Tool}

This mapping exercise proved time consuming because, for most participants, both the methodology and the experience of "negotiating" the mapping in detail were new. Thus several follow-up steps by working groups were needed to generate the outcome shown in Figure 2.

The participants categorized the key actors into three major groups: the Thai State, the "liberation movement," and civil society organizations (CSOs). Obviously, they identified the Thai State and the liberation movement as the main parties to the conflict, while the civil society sector was placed between these two parties in a nearly equidistant position. Within each segment they 
identified a multiplicity of sub-groups. In addition to the three major groups, other actors included politicians, the media, human rights defenders, civil society organizations from outside the region, Thai society in general, Patani's political exiles, international organizations, and foreign governments.

Interestingly, this tool enabled participants to exchange views on the importance of institutions, including the monarchy, which is rarely discussed in public. They also spent significant time discussing in great detail the level of influence, the strategies, and the relationships of all the major actors involved. It turned out that this tool triggered a deep dialogue among the participants. It is noteworthy that some Thai Buddhist participants later admitted that this particular exercise made them realize for the first time that the liberation movement did indeed exist and had played a significant role in the conflict. Of course, not all of them were willing to accept the claim of "liberation," although the term was tolerated by most of the participants.

\section{Onion Tool on Position, Interest, Need, and Fear}

When the onion tool was first introduced, discussion centered on the exact understanding of positions, interests, needs, and fears in similar exercises because these terms overlap significantly and can easily lead to misunderstandings. Nevertheless, their wide use in the negotiation arena has made them important parameters for conflict transformation and peacebuilding.

Following the results of the first tool, the participants decided to focus not only on the two main conflicting actors, but also to apply the tool to the positions, interests, needs, and fears of the civil society sector as well (see Table 1).

This exercise triggered some debate regarding the assessment of the militant Malay Muslim movements, particularly the BRN (Barisan Revolusi Nasional) as one of the main actors in the conflict. The majority of the participants assumed that the BRN's position would be one of merdeka (freedom) as it applies to the formation of their own independent state. However, since there had been no public statement of this claim it remained an open question at the time of the exercise. ${ }^{8}$ Nevertheless, the result of the onion exercise led to an in-depth discussion of the next category of the interests and consideration of the question of how an assessment of the two sides could be bridged in some future peace process. The majority appeared to conclude that the gap between the parties did not appear to be irreconcilable, at least as far as mutual interests were concerned.

The discussion of needs and fears demonstrated the highest potential for facilitating a deeper understanding of each other's underlying concerns. To promote this impact, we introduced a fishbowl setting in which one group (in this case a homogeneous one) talked among themselves about the other side's concerns, while the remaining participants just listened to the conversation in the inner circle. However, in hindsight, perhaps we applied this method a bit too early, because it requires a substantive level of trust to share and listen attentively 
Table 1. Positions, Interests, Needs, and Fears of Main Actors in the Conflict

\begin{tabular}{|c|c|c|c|}
\hline Category & Thai State & Liberation Movement & CSO sector \\
\hline Position & $\begin{array}{l}\text { - Sovereignty and territorial } \\
\text { integrity: Thailand is one } \\
\text { indivisible Kingdom }\end{array}$ & $\begin{array}{l}\text { - Independence from the } \\
\text { Thai State, with its own } \\
\text { Nation State }\end{array}$ & $\begin{array}{l}\text { - Peace and justice } \\
\text { - People's empowerment } \\
\text { and self-determination }\end{array}$ \\
\hline Interest & $\begin{array}{l}\text { - Ensure law and order } \\
\text { through necessary measures } \\
\text { to prevent and suppress } \\
\text { violence } \\
\text { - Centralization and } \\
\text { upholding "Nation, Religion } \\
\text { and Monarchy" that } \\
\text { constitute national security }\end{array}$ & $\begin{array}{l}\text { - Autonomy, political } \\
\text { freedom } \\
\text { - Power to determine } \\
\text { how they live and how } \\
\text { they allocate resources }\end{array}$ & $\begin{array}{l}\text { - Upholding equality; no } \\
\text { discrimination } \\
\text { - Harmony within } \\
\text { pluralistic society } \\
\text { - More power to } \\
\text { determine local affairs }\end{array}$ \\
\hline Need & $\begin{array}{l}\text { - Protection of Thai identity } \\
\text { and dignity of Thai State } \\
\text { - Political stability }\end{array}$ & $\begin{array}{l}\text { - Freedom to live their } \\
\text { lives according to } \\
\text { religious faith and } \\
\text { culture }\end{array}$ & $\begin{array}{l}\text { - Political participation } \\
\text { and recognition }\end{array}$ \\
\hline Fear & $\begin{array}{l}\text { - Losing authority and } \\
\text { territory }\end{array}$ & $\begin{array}{l}\text { - Being assimilated, } \\
\text { ethnically, religiously } \\
\text { and culturally to the } \\
\text { extent of losing their } \\
\text { Malay-Patani identity }\end{array}$ & $\begin{array}{l}\text { - Losing life and being } \\
\text { unsecured }\end{array}$ \\
\hline
\end{tabular}

Figure 3. Simplified Version of Conflict Drivers

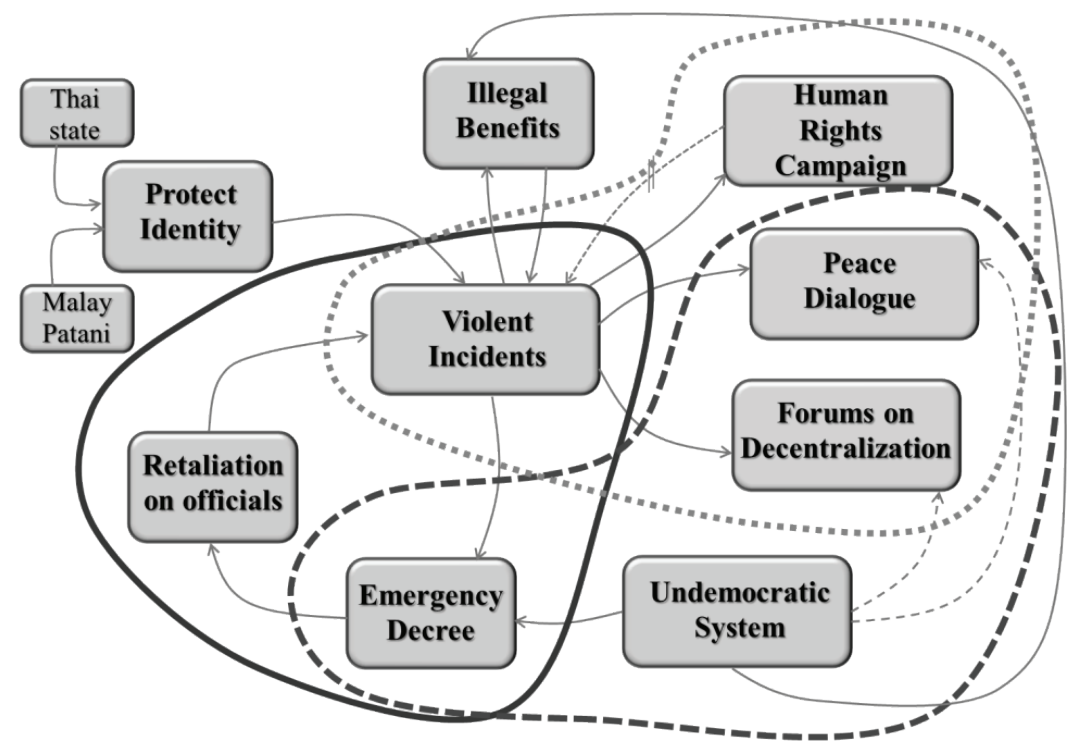

CONFLICT DRIVERS TOOL

— Line A: Violence Circle .... Line B: Peace Efforts - - - Line C: Obstacles to Peace Efforts 
to discourses on basic needs and fears.

The complex system of conflict drivers generated by the participants can be illustrated in a simplified version as shown in Figure 3. The starting point and center of the diagram is Violent Incidents as the key indicators of the protracted conflict. Around this center three loops were identified to indicate connections among the various drivers of the protracted conflict. The first loop (line A) represents incidents of violence. This is an amalgamation of various events including targeted killings and bomb attacks. Participants were of the view that the violence is sparked by a combination of interlinking drivers. Some of these relate to perpetrators' efforts to "defend their identity," be it as a Thai Buddhist or as a Malay Muslim. Besides drivers protecting the cultural identities of each side, there are drivers linked to state officials' retaliatory actions that are perceived, rightly or wrongly, as being of a humiliating nature. Furthermore, the Thai State has enforced an Emergency Decree (which gives security agencies special rights) as an instrument to address violence in the region. Yet the enforcement of the Emergency Decree is one of the factors that can be interpreted as denial of both justice and equal treatment, which in turn spurs retaliation against state officials. And these loops can finally feed upon themselves and create the trap of an ongoing protracted conflict. To break this loop, a radical change of one or the other driver is necessary.

The second loop (line B) is the circle involving conflict resolution efforts that represent attempts to reduce violence. Advocacy campaigns by CSOs to prevent human rights violations have been mounted in response to the actions of some state officials. Peace talks among individuals representing the Thai State and some factions of the Malay Muslim movement-as well as dialogue forums on decentralization-have been attempted as a means of promoting conflict transformation. But so far these efforts have had only limited impact, with the notable exception of efforts to reduce human rights violations. A large group of participants explained away this failure as reflecting the limitations of the Thai political system in terms of effective democratic participation and problemsolving capacity. These factors are summarized in the third loop (line C), which describes specific obstacles to conflict resolution.

\section{Conflict Narratives Tool}

While working on the drivers of conflict some of the participants became lost in the multiplicity of the drivers and the complexities of their interaction. But after the completed mappings were reviewed and efforts were undertaken to make them aware of the possibility to move between "simplification" and "complexification," this tool became an attractive focal point for understanding the essence of the conflict. ${ }^{9}$ It also offered entry points for the discussion of strategies for change. However, in light of the heavy self-reproducing character of this approach, it was decided to revisit it at a later date, after we had reviewed 
other analytical tools.

The participants were divided into three groups based on ethnicity: Malay Muslim, Thai Buddhist, and Thai Chinese. Each group prepared its own narrative on an extended landscape flipchart. The three visualizations of the narrative timelines were then presented and discussed in the plenary. Because this tool aimed to keep the different narratives separate, we had proposed that the first round of the plenary discussion should consist only of questions of clarification and understanding, allowing no immediate debate or comment. This turned out to be a helpful ground rule because the presentation of these fundamentally different narratives generated a long-lasting impact on the participants.

Briefly, the narrative of the Thai Buddhists illustrated that the land in the Deep South had been governed by the (former) Siamese state for a long time, having been populated by diverse groups of people with different ethnicities and religions, many of whom later converted to Islam. Nevertheless, these people of diverse backgrounds had lived together peacefully for centuries until armed guerilla groups were organized to drive a wedge between local residents and to resist the state authority for their self-interest. In contrast, the Malay people's narrative was centered on the agony of a proud ethnic group, inheritors of the glorious history of the former Patani Kingdom. This Kingdom once possessed its own sovereignty and distinct cultural identity before it was subjected to aggression and oppression by the Siamese State. The injustice and discrimination still continues until the present day. These traumas lent legitimacy for the Malay Muslims to rise up and fight for justice.

Turning to the perspective of the Thai Chinese people, their narrative reflected a lack of shared history with the Siamese people. The Malay Muslim participants reacted with surprise at this admission, having assumed that the Chinese living in the area and the Thai Buddhists were similar. The Chinese participants emphasized that their ancestors had also suffered from the former Thai State's policies to assimilate them. Yet they had managed to blend in and coexist with other groups around them. One explanation for this was that they viewed themselves as settlers, and not inhabitants.

For a large number of participants this tool proved to be an eye-opener because for the first time they were confronted with three radically different historical perspectives of the same region. While they had assumed that their perspectives would be different, they had not expected the perspectives to differ so widely. They also expressed surprise that the markers for sequencing the history of the region were so divergent. The team was concerned that the final plenary on this topic might lead to a wide-ranging dispute over what constituted the "true history," but this was not how the discussion unfolded. Although some of the comments indeed pointed in this direction, they represented the voice of a distinct minority. Instead, it appeared that, at least as this stage of engagement, the participants were prepared to learn about these different historical perspectives. 
Figure 4. Context of the Conflict
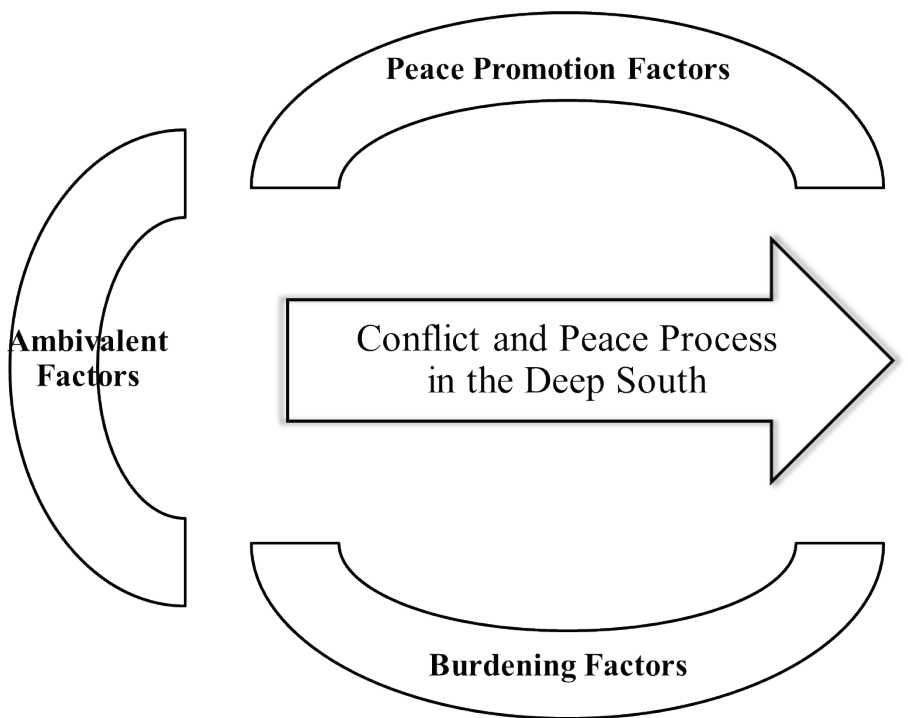

Many of them would return to this experience during several of the follow-up meetings.

No one initiated the idea of trying to combine or merge these narratives. Instead, the attitude was geared more toward learning about all the narratives and gaining a better understanding of how particular historical episodes had become starting points for different perceptions, glorifications, as well as traumatization. The team interpreted this experience as the need to find constructive ways of integrating this divided past into some kind of shared future.

\section{Context Tool}

The fifth workshop focused on the broad dimension of context factors and how they might influence the conflict and future transformation. The tools were used to encourage participants to identify the following three categories of factors: (1) factors conducive to peacebuilding, (2) factors that would obstruct peace efforts, or, in other words, factors that would reinforce the status quo (as of 2012), and (3) ambivalent factors about which it was uncertain at the time whether they would contribute to, or obstruct, peacebuilding. These three factors are illustrated in Figure 4 .

After the participants were divided into groups to analyze the factors in greater detail, they were asked to rank the factors in terms of importance (shown in parenthesis in Table 2).

One interesting result was that the participants emphasized the influence of the changing international environment and the potential weight of the Organization of Islamic Cooperation (OIC) and the Association of Southeast 
Table 2. Priorities of Conflict Context Factors

\begin{tabular}{|c|c|c|}
\hline Ambivalent Factors & Peace Promotion Factors & Burdening Factors \\
\hline $\begin{array}{l}\text { - Succession of the Monarchy } \\
\text { - } 18) \\
\text { - } \underline{\text { Funpact of ASEAN (14) }} \\
\text { support (6) } \\
\text { - Malaysian governational } \\
\text { policy towards the conflict in } \\
\text { the Deep South of Thailand } \\
\text { (4) }\end{array}$ & 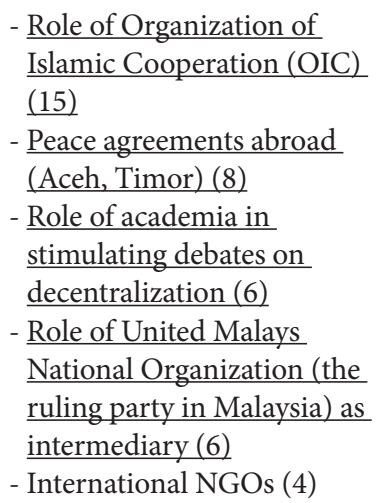 & 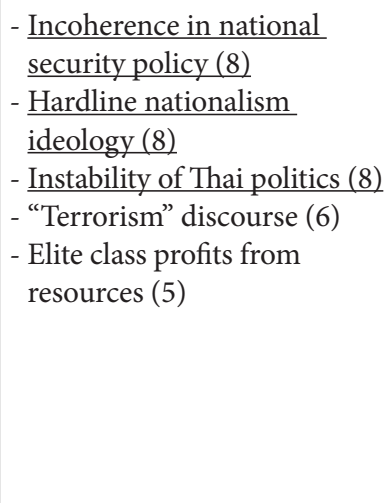 \\
\hline
\end{tabular}

Figure 5. Summary of the Analysis on Conflict in Southern Thailand

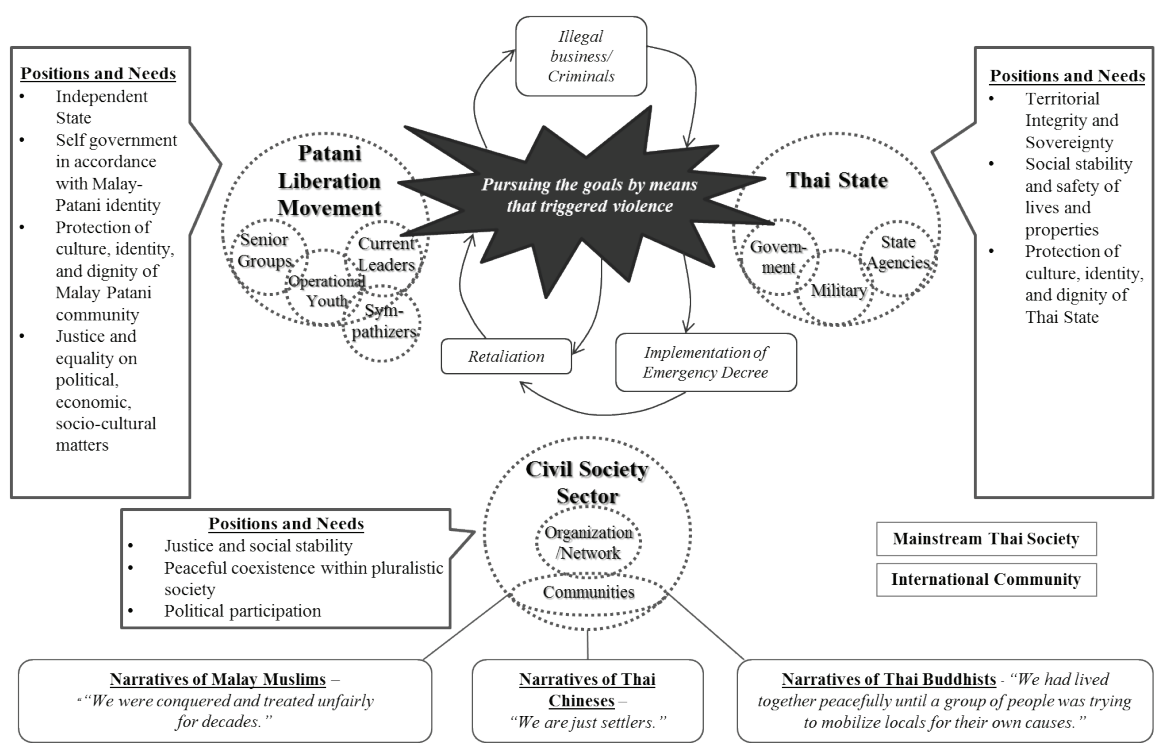

Asian Nations (ASEAN). (The strong positive assessment of the OIC was most likely connected to its actual engagement in the country at the time of the workshop in 2012.) Also, most of them agreed that efforts aimed at conflict transformation should be part of a larger framework of factors that would somehow influence the situation on the ground. 
The diagram in Figure 5 captures some of the essentials of the conflict analysis collectively achieved by the participants. The Thai state, the Patani liberation movement, and the civil society sector comprise three communities as the main actors derived from the Actor-Relationship Mapping Tool. The Onion Tool helped participants to identify positions and interests of the actors while the Narratives Tool enabled them to elaborate the different narratives of Malay Muslim, Thai Buddhist, and Thai Chinese peoples. Factors that fuelled the conflict were discussed with the help of the Drivers of Conflict Tool. Finally, the Context Tool equipped them to analyze the impact of mainstream Thai society and the international community. This diagram was used to summarize the analysis with the participants and to assist reflection on the next steps in joint engagement towards conflict transformation. The feedback of the participants, which will be summarized in the next section, was to a great extent related to the fact that the process encouraged a circular perspective on the conflict; that is, an analysis which reviewed its history, actors, issues, and dynamism from different angles, but always with the aim of exploring and understanding the core drivers and their interaction.

\section{Conclusions: Joint Learning as the Key Component of Peacebuilding}

The IPP process has helped to create and nurture a mixed group of peacebuilders and stakeholders committed to a peaceful transformation of the Southern Thailand conflict. This process started in 2011 with the conceptual inspiration of Ricigliano's network of effective action, which is based on the assumption that a non-hierarchical joint learning process among activists could be a more effective method for promoting peacebuilding than organized structures based on complementarity and collaboration. We were particularly interested in the question of what kind of tools and didactic arrangements would be helpful in enabling persons with different backgrounds vis-à-vis the conflict to engage constructively with one another and to prepare them for undertaking joint activities. Regarding this question, our main conclusion is that joint conflict analysis is indeed a promising tool to prepare and nurture multi-party peace constituencies. Beyond this general observation, we collected several specific insights that ought to improve joint learning, generate shared knowledge, and move towards joint peacebuilding efforts:

1. The sequencing of conflict analysis tools is an important aspect for supporting a process of trust-building interaction and shared knowledge generation. In our case the Mapping of Actors and Relationships served as a useful first tool to allow all participants to share their actor-specific knowledge and to profit from the insights of others without the need for 
any kind of taking sides. The possibility of working towards a "sufficiently consensual" mapping makes this tool particularly attractive for gaining the empowering experience of reaching agreement (albeit limited) across different opinions.

2. As a crucial element for making conflict analysis tools attractive and effective for joint learning, many participants emphasized two aspects: first, that they trigger some kind of "aha" experience of new and sometimes surprising insights, and second, that they can be visualized in a group arrangement to facilitate an in-depth conversation about the shared knowledge generated.

3. Tools that are, by definition, difficult to lead to any early agreement (e.g., the sharing of different interests, feelings, needs, and fears of the parties and their different historical narratives) are nevertheless crucial. They are important for enabling people to change perspectives and to move towards deeper levels of understanding and respect. But these tools should only be introduced after the participants have developed sufficient trust in each other and have collected empowering experiences of arriving at agreements using other tools.

4. For achieving personal trust and confidence building as well as substantive results using joint conflict analysis, our experience is that it helps to regularly shift the interaction in the workshops between work in homogeneous and heterogeneous identity groups (in addition to the traditional mode of shifting between plenaries and breakout groups). This approach acknowledges and respects differences, but also encourages the participants to change perspectives and find ways of communicating these differences in a constructive manner.

5. At the end of the day, the most critical tools are those which help the participants better understand how the conflict emerged and became protracted because none of the driving parties acting alone could contain or control the conflict. This aspect is best captured in tools that emphasize the systemic character of the conflict, such as mapping the drivers of conflict. Reaching this stage in a joint conflict analysis is critical because it can trigger ambivalent reactions in the participants. On the one hand, it underlines the self-fuelling dynamism of the conflict and can trigger a feeling of resignation in light of these strong forces. On the other hand, it offers a number of entry points for peaceful change while providing the participants with an understanding that efforts for negative and positive peace are closely connected with each other.

As for the unresolved challenges for practical peace work and open questions for further research, we hope to learn from colleagues engaged in similar initiatives. To this end we have identified three key points. First, the initial challenge is 
about the scaling up of this kind of work. The approach of joint learning in a mixed group of peacebuilders and stakeholder representatives was possible in a workshop setting of, at most, 60 people. The pioneering character of the initiative and this particular size enabled us to ensure a sufficiently broad composition representing the identity groups and partisan backgrounds of the participants. As previously mentioned, many of the participants subsequently made use of the tools and the experiences in their own constituent organizations and networks. But they were often confronted by the problem that these constituencies were rather homogeneous, which meant that they often lacked the crosscutting element of the joint learning approach. Second, another challenge, which is partly connected to the first one, is how to ensure the sufficient involvement of Thai Buddhist and Thai Chinese people living in the three southernmost provinces. While they represent the overwhelming majority of people in Thailand, these groups are influential minorities in the region. Many of them are torn between supporting some kind of status quo policy to ensure their security and wellbeing, on the one hand, and the wish to contribute to a new peaceful settlement that would end the violence, on the other. Lastly, the shift from the phase of conflict analysis to envisioning and actually working on conflict transformation has energized the IPP participants, particularly due to the fact that the Thai government and the BRN initiated an official peace dialogue process in 2013. How this Track-1 process will be taken forward under the current political circumstances facing the country is an open question. But it is likely that civil society actors and Malay Muslim political activists will play a more visible role in preventing the situation on the ground from deteriorating again, as has happened in many comparable situations when a failed Track-1 effort has led to a reescalation of violence. From the perspective of the IPP a key question is, therefore, how to best make use of this model of joint learning with respect to the future. This is what inspires our current work, and we welcome any feedback and suggestions our readers may have.

\section{Notes}

1. The terms "Deep South of Thailand" and "Southern Thailand" are used in this article interchangeably to represent the region comprised by the three most southern provinces of Thailand (Pattani, Narathiwat, and Yala) plus four districts of Songkla Province with a Malay Muslim majority population. Occasionally we will also use the terms Pattani (official Thai name) or Patani (Malay spelling) for the former Kingdom, and Sultanate as a name for the overall region. The IPP generated the term Pat $(t) a n i$ to emphasize the need for an inclusive term acknowledging the multicultural character of the region. The authors are personally involved in the work of the IPP. We are grateful to our colleagues for their inspiring collaboration and feedback on this field note, but the responsibility for any 
shortcomings rests with us.

2. The group comprised the Center for Conflict Studies and Cultural Diversity (CSCD) and the Institute for Peace Studies (IPS) at Prince of Songkla University (PSU), the Center for Peace and Conflict Studies (CPCS) at Chulalongkorn University, the Peace Information Center (PIC) at Thammasat University, the Institute of Human Rights and Peace Studies at Mahidol University, the Office of Peace and Governance at King Prajadhipok's Institute (KPI), Deep South Watch (DSW), and the Berghof Foundation Liaison Bangkok.

3. Lisa Schirch has recently proposed that the term "lens" might be more appropriate than "tools" to emphasize the need for understanding the holistic character of conflict instead of taking it apart $(2013,24)$ - a good point. Our experience though is that for a capacity-building event the term "tool" has a strong appeal for the participants insofar as their emphasis is on learning.

4. As in many other similar situations, the terminology on and around the "conflict" ("insurgency" or khwam mai sangop [disturbance or unrest]) is contested. We will use the academically widely accepted term "conflict."

5. The population in the Deep South of Thailand is comprised of three ethno-religious groups: Thai-Buddhist, Malay-Muslim, and Chinese. Based on data from Ministry of Interior, as of 2004, the percentage of Muslims in the region is $85.16 \%$ and that of Buddhists $14.53 \%$. Most of the ethnic Chinese are Buddhists. All ethno-religious groups are considered Thai citizens. The Malay-Muslims are the majority in the region, but in the country as a whole they are a minority.

6. "Narrative" in this joint learning process is defined as collective memories of one particular group of people sharing any given identity. It is a set of stories about the conflict history seen through their respective lenses. These stories lend legitimacy to actions by each side, why they decide to do certain things, including pursuing armed struggle or using force to settle conflict. Typically there are at least two perspectives to a narrative: one side features the narrator themselves as victims, with numerous grievances, while the other emphasizes the legitimacy of their side.

7. This term is used differently with respect to the exact definition of "sufficient." A widely used interpretation is that a majority of all participating conflict groups agrees with an outcome or decision.

8. During the time of the workshop, the peace dialogue process between representatives of the Royal Thai Government and the BRN had not yet been initiated. The General Consensus on Peace Dialogue Process between the two parties was later signed on February 28, 2013.

9. In systemic discourse these focal points or clusters are also called "centers of gravity" (Schirch 2013, 24) or "attractors" (Coleman 2011, 77).

\section{References}

Abuza, Zachary. 2009. Conspiracy of Silence: The Insurgency in Southern Thailand. Washington, D.C.: United States Institute of Peace Press.

Barter, Shane J. 2011. "Strong State, Smothered Society: Explaining Terrorist Violence in Thailand's Deep South." Terrorism and Political Violence 23 (2): 213-232.

Chaijaroenwatana, Bussabong, Srisompob Jitpiromsri, Thammasat Sotthibandhu, 
Zakee Phithakkumpol, Yasmin Satta, Samatcha Nilaphatama, Chayanit Poonyarat, Farida Panjor, Romadon Panjor, Muhammad A. Pathan, Norbert Ropers, Jularat Damrongviteetham, and Mathus Anuvatudom. 2013. Kan Pued Phuenthi Klang Sang Santiphap Chak Khon Nai Phai Tai Boribot Khong Krabuankan Santiphap Chaidantai/ patani [The initiative of the Insider Peacebuilders Platform in the Context of the Southern Thailand/Patani Peace Process]. Hat Yai: Prince of Songkla University Press. Chigas, Diana, and Peter Woodrow. 2009. "Envisioning and Pursuing Peace Writ Large."

In Peacebuilding at a Crossroads? Dilemmas and Paths for Another Generation, eds. B. Schmelzle and M. Fischer. Berghof Handbook Dialogue No. 7. Berlin: Berghof Research Center, 47-58.

Coleman, Peter T. 2011. The Five Percent: Finding Solutions to Seemingly Impossible Conflicts. New York: Public Affairs.

Fisher, Simon, Dekha Ibrahim Abdi, Jawed Ludin, Richard Smith, Steve Williams, and Sue Williams. 2005. Working with Conflict Skills and Strategies for Action, 3rd ed. London: Zed Books.

Hiscock, Duncan, and Teresa Dumasy. 2012. From Conflict Analysis to Peacebuilding Impact: Lessons from the People's Peacemaking Perspectives Project. London: Conciliation Resources, Saferworld.

IPP (Insider Peacebuilders Platform). 2014. "How Can the Peace Process be Taken Forward?" Peace Media Day, PPP101, Pattani, February 27-28. http://www. deepsouthwatch.org/en/node/5446 (accessed October 4, 2014).

Jitpiromsri, Srisompob. 2014. "An Inconvenient Truth about the Deep South Violent Conflict: A Decade of Chaotic, Constrained Realities and Uncertain Resolution.” July 2. http://www.deepsouthwatch.org/en/node/5904 (accessed October 4, 2014).

Jitpiromsri, Srisompob, and Anders Engvall. 2013. A Meaningful Peace: Ramadan Ceasefire Assessment. Pattani: Deep South Watch. http://www.deepsouthwatch.org/node/4720 (accessed October 4, 2014).

Joll, Christopher. 2010. "Religion and Conflict in Southern Thailand: Beyond Rounding Up the Usual Suspects." Contemporary Southeast Asia 32 (2): 258-279.

Jory, Patrick, ed. 2013. Ghosts of the Past in Southern Thailand: Essays on the History and Historiography of Patani. Singapore: National University of Singapore.

Koerppen, Daniela, Norbert Ropers, and Hans J. Giessmann. 2011. The Non-linearity of Peace Processes: Theory and Practice of Systemic Conflict Transformation. Opladen \& Famington Hills, MI: Barbara Budrich Publishers.

Lamey, Jay. 2013. "Peace in Patani? The Prospect of a Settlement in Southern Thailand." Stability: International Journal of Security and Development 2 (2): Art. 33, 1-17. http:// www.stability journal.org/rt/printerFriendly/sta.bt/98_(accessed October 9, 2013).

Leonhardt, Manuela. 2002. Conflict Analysis for Project Planning and Implementation. Bonn: German Technical Cooperation (GTZ).

McCargo, Duncan. 2009. Tearing Apart the Land: Islam and Legitimacy in Southern Thailand. Singapore: National University of Singapore.

McCargo, Duncan. 2012. Mapping National Anxieties: Thailand's Southern Conflict. Copenhagen: NIAS Press.

McCargo, Duncan. 2014. "Southern Thailand: From Conflict to Negotiations?" Lowy Institute Analysis. Sydney: Lowy Institute for International Policy.

Reich, Hannah. 2006. "Local Ownership' in Conflict Transformation Projects: Partnership, 
Participation or Patronage?” Occasional Paper 27. Berlin: Berghof Foundation .

Ricigliano, Robert. 2003. "Networks of Effective Action: Implementing an Integrated Approach to Peacebuilding." Security Dialogue 34 (4): 445-462.

Ricigliano, Robert. 2012. Making Peace Last: A Toolbox for Sustainable Peacebuilding.

Boulder, London: Paradigm Publishers.

Ropers, Norbert. 2000. “Ziviles Krisenmanagement: Handlungsebenen, Arbeitsfelder und

Zeitperspektiven" [Civilian Crisis Management: Levels of Actions, Working Areas and

Time Frames]. In Europas Beitrag zum Frieden, ed. Austrian Study Centre for Peace and Conflict Resolution. Muenster: LIT, 29-44.

Satha-Anand, Chaiwat, ed. 2009. Imagined Land? The State and Southern Violence in

Thailand. Asahi-cho, Fucha-city: Tokyo University of Foreign Studies, Research Institute for Languages and Cultures of Asia and Africa.

Schirch, Lisa. 2013. Conflict Assessment \& Peacebuilding Planning: Toward a Participatory Approach to Human Security. Boulder, CO: Kumarian Press.

SIDA (Swedish International Development Cooperation Agency). 2006. Manual for Conflict Analysis. Division for Peace and Security through Development Cooperation, Methods Document. Stockholm: SIDA.

SDC (Swiss Agency for Development and Cooperation). 2005. Conflict Sensitive Programme Management, CSPM: Integrating Conflict Sensitivity and Prevention of Violence into SDC Programmes. Bern: SDC.

Tuansiri, Ekkarin, and Don Pathan. 2014. Negotiating the Future of Patani. Pattani: Patani Forum.

USAID (United States Agency for International Development), Conflict Management and Mitigation Office. 2012. Conflict Assessment Framework (CAF) 2.0. Washington, D.C.: USAID.

Norbert Ropers is Senior Research Fellow, Center for Conflict Studies and Cultural Diversity, Prince of Songkla University, Pattani, Thailand, and Program Director, Asia, Berghof Foundation, Bangkok/ Berlin. From 2001 to 2008, he headed the Resource Network for Conflict Studies and Transformation in Sri Lanka. Previously, he worked for academic and civil society institutions in Germany and the United Kingdom engaged in peacebuilding work. His most recent book publication is (edited with Daniela Koerppen and Hans J. Giessmann) The Non-Linearity of Peace Processes: Theory and Practice of Systemic Conflict Transformation (Budrich, 2011). E-mail: u.ropers@berghof-foundation.org

Mathus Anuvatudom is based at the Office of Peace and Governance, King Prajadhipok Institute, Bangkok, Thailand. He has engaged in peacebuilding work on political conflict and national reform efforts. Regarding the conflict in the Deep South of Thailand, he is involved in organizing dialogue initiatives as well as forming a safety net comprised of civil society activists and state officials for the current peace process. E-mail: mathus_a@hotmail.com 